\title{
Relationship between cloud radiative forcing, cloud fraction and cloud albedo, and new surface-based approach for determining cloud albedo
}

\author{
Y. Liu, W. Wu, M. P. Jensen, and T. Toto \\ Brookhaven National Laboratory, Bldg. 815E, Upton, NY11973, USA \\ Received: 20 January 2011 - Published in Atmos. Chem. Phys. Discuss.: 16 February 2011 \\ Revised: 9 July 2011 - Accepted: 11 July 2011 - Published: 21 July 2011
}

\begin{abstract}
This paper focuses on three interconnected topics: (1) quantitative relationship between surface shortwave cloud radiative forcing, cloud fraction, and cloud albedo; (2) surface-based approach for measuring cloud albedo; (3) multiscale (diurnal, annual and inter-annual) variations and covariations of surface shortwave cloud radiative forcing, cloud fraction, and cloud albedo. An analytical expression is first derived to quantify the relationship between cloud radiative forcing, cloud fraction, and cloud albedo. The analytical expression is then used to deduce a new approach for inferring cloud albedo from concurrent surfacebased measurements of downwelling surface shortwave radiation and cloud fraction. High-resolution decade-long data on cloud albedos are obtained by use of this surface-based approach over the US Department of Energy's Atmospheric Radiaton Measurement (ARM) Program at the Great Southern Plains (SGP) site. The surface-based cloud albedos are further compared against those derived from the coincident GOES satellite measurements. The three long-term (19972009) sets of hourly data on shortwave cloud radiative forcing, cloud fraction and cloud albedo collected over the SGP site are analyzed to explore the multiscale (diurnal, annual and inter-annual) variations and covariations. The analytical formulation is useful for diagnosing deficiencies of cloudradiation parameterizations in climate models.
\end{abstract}

\section{Introduction}

Quantifying the impact of clouds on the Earth's radiation budget has been the subject of intensive research for several decades (Schneider, 1972; Charlock and Ramanathan, 1985;

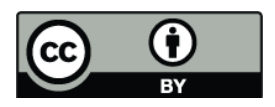

Correspondence to: Y. Liu (lyg@bnl.gov)
Ramanathan, 1987; Laszlo and Pinker, 1993; Ramanathan et al., 1989a, b; Harrison et al., 1990; Arking, 1991, 1999; Wielicki et al., 1995; Rossow and Zhang, 1995; Raschke et al., 2005). One of the quantities that have been increasingly used to gauge the radiative impact of clouds is cloud radiative forcing (CRF) defined as the difference between clear-sky and all-sky net radiation fluxes (e.g., Ellis, 1978; Coakley and Baldwin, 1984; Charlock and Ramanathan, 1985; Ramanathan, 1987; Cess and Potter, 1987). An advantage of using CRF is that it can be readily obtained from satellite radiative measurements or calculated in global climate models (GCMs). Comparison of model-simulated CRF against satellite observations at the top of atmosphere (TOA) have proven to be instrumental in evaluation of climate models and the identification of cloud feedbacks and parameterizations as the key factors contributing to the large uncertainty in GCM climate sensitivity (Cess et al., 1997, 2001; Potter and Cess, 2004; Soden et al., 2004; Stephens, 2005; Bony et al., 2006).

Despite its great utility, CRF - and its variation with temperature in studies of cloud feedbacks, alone is not enough for fully understanding cloud-radiation interactions and their effects on climate. Further progress requires relating CRF to other cloud properties such as cloud fraction and cloud albedo. Although it has been long recognized that CRF is related intimately to cloud fraction and cloud albedo and some efforts have been devoted to exploring their relationships (Charlock and Ramanathan, 1985; Harrison et al., 1990), our understanding has been largely qualitative. The quantitative relationship between CRF, cloud fraction and cloud albedo remains elusive.

The roles of cloud fraction and cloud albedo in shaping the Earth's climate had actually been investigated before the introduction of CRF - already in the 1970s (Arakawa, 1975; Schneider, 1972), and continue to defy satisfactory understanding and parameterization (Bony and Dufresne, 2005).

Published by Copernicus Publications on behalf of the European Geosciences Union. 
For example, Bender et al. (2006) compared the results of global albedo from $22 \mathrm{GCMs}$ and two satellites, and found that GCM-derived values not only exhibit a large spread but also consistently higher values than those observed by the two satellites. These differences between observations and models are likely due to inadequate GCM parameterizations related to determination of cloud fraction and/or cloud albedo.

To fill this gap, here we first introduce the concept of relative CRF after discussing deficiencies of the traditional CRF. Then we derive an analytical formulation of the relationship between the relative CRF, cloud fraction, and cloud albedo. A new method based on this analytical relationship is presented to infer cloud albedo from measurements of relative CRF and cloud fraction. By use of the analytical formulation, decade-long hourly data on relative CRF cloud albedo are generated from the concurrent surface-based measurements of downwelling shortwave radiation flux and cloud fraction collected by the US Department of Energy's Atmospheric Radiation Measurement (ARM) program at the Southern Great Plain (SGP) site since 1997 (Stokes and Schwartz, 1994; Ackerman and Stokes, 2003). The surface-based cloud albedo data are evaluated in comparison of the coincident and collocated satellite measurements. The decadelong data on relative cloud CRF, cloud fraction and cloud albedo are examined to determine their multiscale variations and covariations.

\section{Relative cloud radiative forcing and its relationship with cloud fraction and cloud albedo}

\subsection{Concept of relative cloud radiative forcing}

Cloud radiative forcing (CRF) was first introduced to study radiation budgets measured with satellites at the top of atmosphere (TOA) (Ellis, 1978; Coakley and Baldwin, 1984; Charlock and Ramanathan, 1985; Ramanathan, 1987; Cess and Potter, 1987).The concept of surface CRF has been later applied to surface-based radiation measurements (Dong et al., 2006; Mace et al., 2006; Mace and Benson, 2008). Despite its usefulness and popularity, the CRF thus defined suffers from the drawback of being affected by factors other than clouds (e.g., solar zenith angle, definition of what constitutes a clear-sky reference, and specification of the surface albedo), and much effort has been devoted to minimizing the effects of these non-cloud factors on computation of the CRF (Imre et al., 1996; Li and Trishchenko, 2001; Vavrus, 2006; Betts and Viterbo, 2005; Betts, 2007; Betts et al., 2009). Among existing attempts, the non-dimensional metric proposed by Betts and his co-workers is probably the best, and is detailed below for the surface shortwave CRF.

The surface shortwave CRF $\left(F_{\text {cld }}\right)$ is defined in terms of downwelling flux such that,

$$
F_{\text {cld }}=F_{\text {all }}^{\mathrm{dn}}-F_{\text {clr }}^{\mathrm{dn}}
$$

where $F_{\text {all }}^{\mathrm{dn}}$ and $F_{\text {clr }}^{\mathrm{dn}}$ denote the all-sky and clear-sky surface downwelling SW radiation fluxes, respectively, with positive values being indicative of downward fluxes. Replacing net flux with downwelling flux reduces the effect of surface albedo (see Vavrus, 2006 for more discussion). To further minimize the effects from other non-cloud factors, Betts and Viterbo (2005) proposed a non-dimensional measure for the surface CRF defined as (see also Betts, 2007; Betts et al., 2009),

$\alpha_{\mathrm{cld}}^{\mathrm{SRF}}=-\frac{F_{\mathrm{cld}}}{F_{\mathrm{clr}}^{\mathrm{dn}}}=1-\frac{F_{\mathrm{all}}^{\mathrm{dn}}}{F_{\mathrm{clr}}^{\mathrm{dn}}}$.

The minus sign is introduced to reflect that the effect of shortwave CRF on climate is cooling $\left(F_{\text {cld }}<0\right)$ and a positive $\alpha_{\text {cld }}^{\mathrm{SRF}}$ is more convenient. They named $\alpha_{\text {cld }}^{\mathrm{SRF}}$ as the effective cloud albedo, as the dependence of the net shortwave radiative flux on $\alpha_{\text {cld }}^{\mathrm{SRF}}$ can be described in a mathematical form similar to surface albedo $\alpha_{\text {srf }}$

$F_{\text {all }}^{\text {net }}=F_{\text {all }}^{\text {dn }}-F_{\text {all }}^{\text {up }}=\left(1-\alpha_{\text {srf }}\right)\left(1-\alpha_{\text {cld }}^{\mathrm{SRF}}\right) F_{\text {clr }}^{\text {dn }}$.

It is noteworthy that as will become evident later, actually $\alpha_{\text {cld }}^{\mathrm{SRF}}$ is approximately a product of cloud fraction and cloud albedo, and that the variation of $\alpha_{\text {cld }}^{\mathrm{SRF}}$ conforms more closely to that of cloud fraction than cloud albedo. Similar quantities were also referred to as cloudiness index (O'Malley and Duchon, 1996) and all-sky shortwave transmission (Dong et al., 2006). To avoid the potential confusion and misunderstanding that $\alpha_{\mathrm{cld}}^{\mathrm{SR}}$ is more related to either cloud albedo or cloud fraction, $\alpha_{\text {cld }}^{\mathrm{SRF}}$ will be referred to as the relative cloud radiative forcing in this paper.

\subsection{Analytical formulation}

Betts and his coworkers (Betts and Viterbo, 2005; Betts, 2007; Betts et al., 2009) examined $\alpha_{\text {cld }}^{\mathrm{SRF}}$ derived from the International Satellite Cloud Climatology Project (ISCCP) data (Rossow and Schiffer, 1991) over several river basins in comparison with those from different reanalysis datasets (ERA40 and ERA-Interim). Although attempts have been made to connect $\alpha_{\text {cld }}^{\mathrm{SRF}}$ to cloud fraction and cloud albedo empirically, the quantitative relationship between the three quantities still remains elusive theoretically, and is a focus of this section.

As a first-order approximation, the atmosphere above the region of interest is considered to comprise a single homogeneous cloud layer with cloud fraction $f$. For this simplified atmosphere, the all-sky surface downwelling shortwave radiation flux is given by

$F_{\text {all }}^{\mathrm{dn}}=f F_{\text {cld }}^{\mathrm{dn}}+(1-f) F_{\mathrm{clr}}^{\mathrm{dn}}$

This single-layer cloud model, or its equivalent, has been widely used in studies involving radiation transfer in partly cloudy environment, e.g., in studies of radiation energy budget and cloud radiative forcing (Ramanathan, 1987; Ramanathan et al., 1989a, b) and in satellite retrievals for partly 
cloudy pixels (Coakley et al., 2005). Equation (4a) can be further reduced to

$F_{\text {all }}^{\mathrm{dn}}=\left(1-\alpha_{\mathrm{r}}\right)\left(1-\alpha_{\mathrm{a}}\right) f F_{\mathrm{clr}}^{\mathrm{dn}}+(1-f) F_{\mathrm{clr}}^{\mathrm{dn}}$,

where $\alpha_{\mathrm{r}}$ and $\alpha_{\mathrm{a}}$ denote the cloud albedo and absorptance, respectively. Substitution of Eq. (4b) into Eq. (2) yields the following expression:

$\alpha_{\mathrm{cld}}^{\mathrm{SRF}}=\left(\alpha_{\mathrm{r}}+\alpha_{\mathrm{a}}-\alpha_{\mathrm{r}} \alpha_{\mathrm{a}}\right) f$.

Equation (5a) reveals that $\alpha_{\text {cld }}^{\mathrm{SRF}}$ is an increasing function of $f, \alpha_{\mathrm{r}}$, and $\alpha_{\mathrm{a}}$, which becomes more evident by ignoring the second-order term, $\alpha_{\mathrm{r}} \alpha_{\mathrm{a}}$, i.e.,

$\alpha_{\text {cld }}^{\mathrm{SRF}}=\left(\alpha_{\mathrm{r}}+\alpha_{\mathrm{a}}\right) f$.

Furthermore, because $\alpha_{\mathrm{a}}$ is generally much less than $\alpha_{\mathrm{r}}$ (Gautier and Landsfeld, 1997), neglect of shortwave absorption further simplifies Eq. (5b) to

$\alpha_{\mathrm{cld}}^{\mathrm{SRF}}=\alpha_{\mathrm{r}} f$.

Equation (5c) reveals that $\alpha_{\mathrm{cld}}^{\mathrm{SRF}}$ is essentially a product of $f$ and $\alpha_{\mathrm{r}}$, and $\alpha_{\text {cld }}^{\mathrm{SRF}}=\alpha_{\mathrm{r}}$ under the overcast sky with $f=1$. Empirical evidence for the latter prediction was documented in an earlier study (Shi, 1994). Shi also introduced the concept of $\alpha_{\text {cld }}^{\mathrm{SRF}}$ as defined by Eq. (2), but only for the overcast scenario where $f=1$. In this sense, Eq. (5c) is a generalization of Shi's work.

Note that a single-layer cloud is assumed in the above formulation. When the region of interest is affected by multilayer clouds, the formulation is expected to hold, but for an effective single-layer cloud with effective cloud properties (Ramanathan, 1987). More discussions on the assumptions underlying Eq. (5c) including multilayer clouds and effective cloud properties are deferred to Sect. 3.3.1.

\section{Cloud albedo from surface-based observations}

\subsection{Approach}

Relative to cloud fraction and CRF, cloud albedo is much less measured and known, hindering investigation of cloudclimate interactions and aerosol indirect effects. Probably the most direct way to measure cloud albedo is using instrumented aircraft (Griggs, 1968; Salomonson and Marlatt, 1968; Hayasaka et al., 1995); but, such aircraft-based in situ measurements are limited in both time and space. Long-term global records of albedo have primarily relied on satellite (Wielicki et al., 2005) and earthshine measurements (Palle et al., 2003, 2009); however, both actually measure global albedo that depends not just on cloud albedo, but on cloud fraction and surface reflective properties as well. Several additional issues on satellite and earthshine measurements were discussed in Loeb et al. (2007). Seeking an adequate satellite-based approach to estimating cloud albedo is still an area of active research (Bender et al., 2011).

An alternative surface-based approach that permits longterm measurements of cloud albedo cannot be overemphasized. An approach that capitalizes on surface-based remote sensing techniques as used at the ARM SGP site is even more desirable in view of the widely demonstrated fidelity of these remote sensors and high temporal sampling resolution (Stokes and Schwartz, 1994; Ackerman and Stokes, 2003). Equation (5c) suggests just such a technique if $\alpha_{\text {cld }}^{S \mathrm{RF}}$ and $f$ can be measured simultaneously, i.e.,

$\alpha_{\mathrm{r}}=\frac{\alpha_{\mathrm{cld}}^{\mathrm{SRF}}}{f}$.

ARM has provided continuous measurements of multiple quantities essential to cloud-radiation interactions by integrating multiple surface-based remote sensors at the SGP site. Especially useful to this study is the surface shortwave radiation value-added product (VAP) generated by Long and his co-workers (Long and Ackerman, 2000; Long et al., 2006). This VAP is based on measurements collected by the Solar and Infrared Radiation System (SIRS) since 25 March 1997, and contains all the data necessary for estimating $\alpha_{\mathrm{cld}}^{\mathrm{SRF}}$ and cloud albedo, including surface all-sky downwelling shortwave radiation fluxes, surface clear-sky downwelling shortwave radiation fluxes, and cloud fraction. The data are quality-controlled and quasi-continuous with 15 min temporal resolution. We first use these data to derive $\alpha_{\text {cld }}^{\mathrm{SRF}}$ by applying the data on surface downwelling all-sky and clear-sky radiation fluxes to Eq. (2), and then substitute $\alpha_{\text {cld }}^{\mathrm{SRF}}$ and $f$ into Eq. (6) to obtain the data on cloud albedo.

Note that the surface-based cloud fraction reported in the SIRS VAP actually is the fractional sky cover estimated using the methodology presented in Long et al. (2006). Briefly, the method exploits the effect of clouds on diffuse downwelling SW radiation. It first identifies the clear-sky conditions (sky cover of zero) and then screens for overcast cases (sky cover of one). For the rest of the data that survive the screening, the sky cover is calculated from an equation that expresses the sky cover as a function of the normalized diffuse cloud effect defined as the difference between the measured all-sky and corresponding clear-sky diffuse irradiance normalized by the clear-sky total downwelling irradiance. This equation is obtained by regressing sky fraction measurements by a whole sky imager to the corresponding measurements of the normalized diffuse cloud effect. More discussion on the surfacebased cloud fraction is referred to Sect. 3.2

\subsection{Comparison with satellite-derived cloud albedo}

The NASA Langley cloud and radiation group (Minnis et al., 2008a) derived broadband shortwave albedo and cloud fraction from GOES-8/11 narrowband observations on a $0.5^{\circ} \times 0.5^{\circ}$ grid over the SGP domain by using narrowband-to-broadband conversion functions (Minnis and 


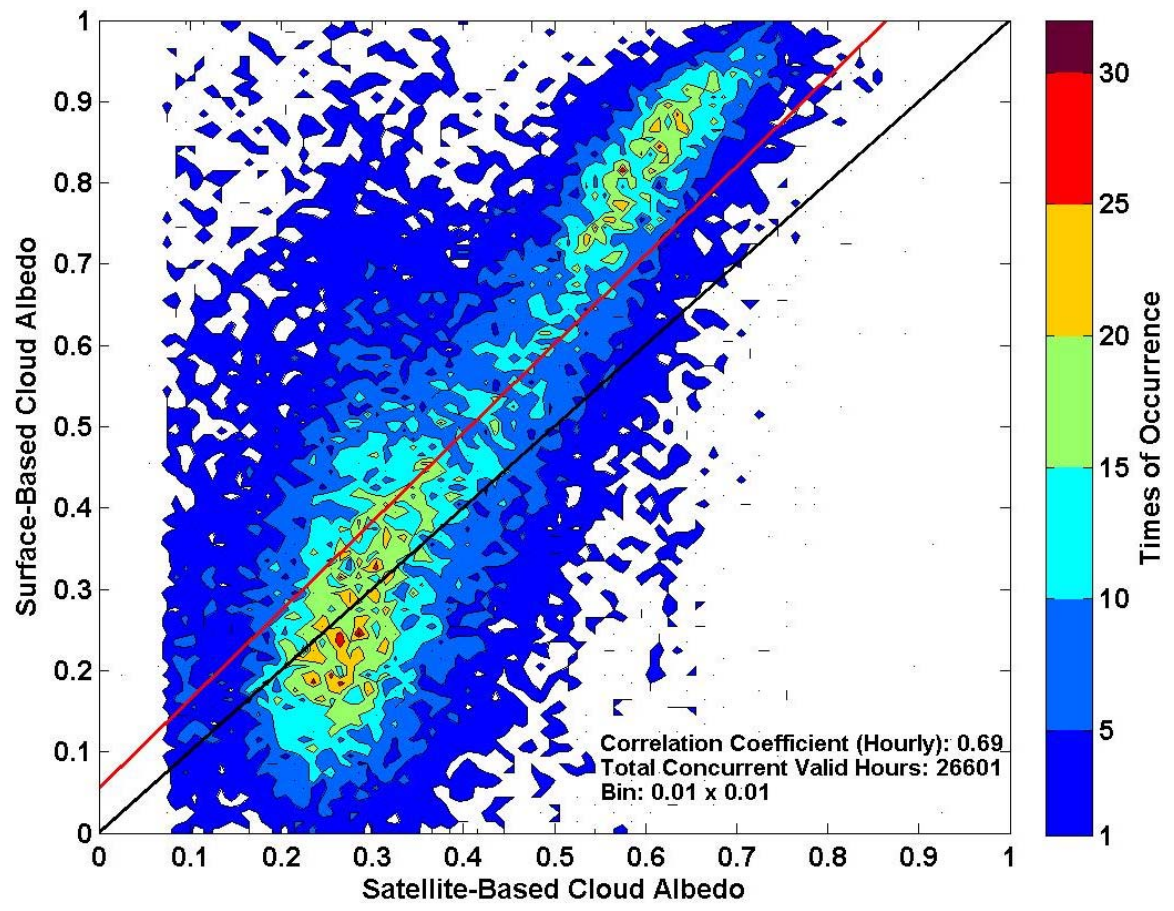

Fig. 1. Comparison of the surface-based cloud albedo with those derived from the GOES satellite. The red and black lines represent the linear fit to all the data points and perfect match, respectively.

Smith, 1998). Briefly, an individual $0.5^{\circ} \times 0.5^{\circ}$ grid includes about 150 pixels of spatial resolution $4 \mathrm{~km}$; a pixel is classified as clear or cloudy by use of a sequence of criteria based upon variations from an observed background state including the surface albedo characteristics (Minnis et al., 2008b). Cloud fraction for each grid is obtained as the fractional occurrence of cloudy pixels on this grid. To best match with the sampling scales of the SIRS data collected at the SGP central facility $\left(36.36^{\circ} \mathrm{N}, 97.29^{\circ} \mathrm{W}\right)$, we choose the single nearest satellite grid $\left(36.25-36.75^{\circ} \mathrm{N}, 97.25-97.75^{\circ} \mathrm{W}\right)$ in comparison with the SIRS cloud albedo.

For the single layer cloud model with cloud fraction $f$ as described by Eq. (4a), it can be shown that the total scene albedo is given by

$\alpha=f \alpha_{\mathrm{r}}+(1-f) \alpha_{\mathrm{clr}}$,

where $\alpha_{\mathrm{clr}}$ is the clear-sky albedo. This equation was used and verified by Cess (1976) in investigation of the meridional distributions of zonally averaged values of total albedo, cloud fraction and cloud albedo. Rearranging Eq. (7a) leads to the expression for deriving cloud albedo:

$\alpha_{\mathrm{r}}=\frac{\alpha}{f}-\frac{1-f}{f} \alpha_{\mathrm{clr}}$.

To validate the new surface-based approach, we calculate satellite-based cloud albedo by applying Eq. (7b) to the GOES-measured hourly total scene albedo, cloud fraction and clear-sky albedo. A total of $26601 \mathrm{~h}$ are found to have coincident data from both the surface and satellite measurements with $f>0$. Figure 1 compares all the 26601 hourly pairs of cloud albedo in terms of the joint occurrence frequency with a $0.01 \times 0.01$ resolution. For reference also shown are the linear fit from the scatterplot of all the points (red line) and the diagonal line of perfect agreement (black). Several points are evident from this figure. First, the two sets of cloud albedo data are correlated to each other reasonably well with a correlation coefficient of 0.69 . The favorable agreement between the surface-based and satellite-based cloud albedo is encouraging in view of the uncertainties in both satellite-and surface-based retrievals and the high temporal resolution of one hour. Second, the relationship is not diagonally linear as expected from a perfect match. Based on the best fit, the surface-based cloud albedo is always higher than the satellite-based cloud albedo, and the discrepancy slightly increases with increasing cloud albedo. An analysis of the joint frequency reveals some additional features. There are two clusters of high occurrence frequency, one around the satellite-based cloud albedo of $\sim 0.25$ and the other around the satellite-based cloud albedo of $\sim 0.65$. For the low-albedo cluster, some surface-based cloud albedos are relatively smaller than the corresponding satellitebased cloud albedos, resulting in a different slope from the rest. The overall slope of the curve describing the data of peak occurrences appears steeper than the best linear fit as well. It is interesting to note that there is extra value in showing joint frequencies together with the commonly used 


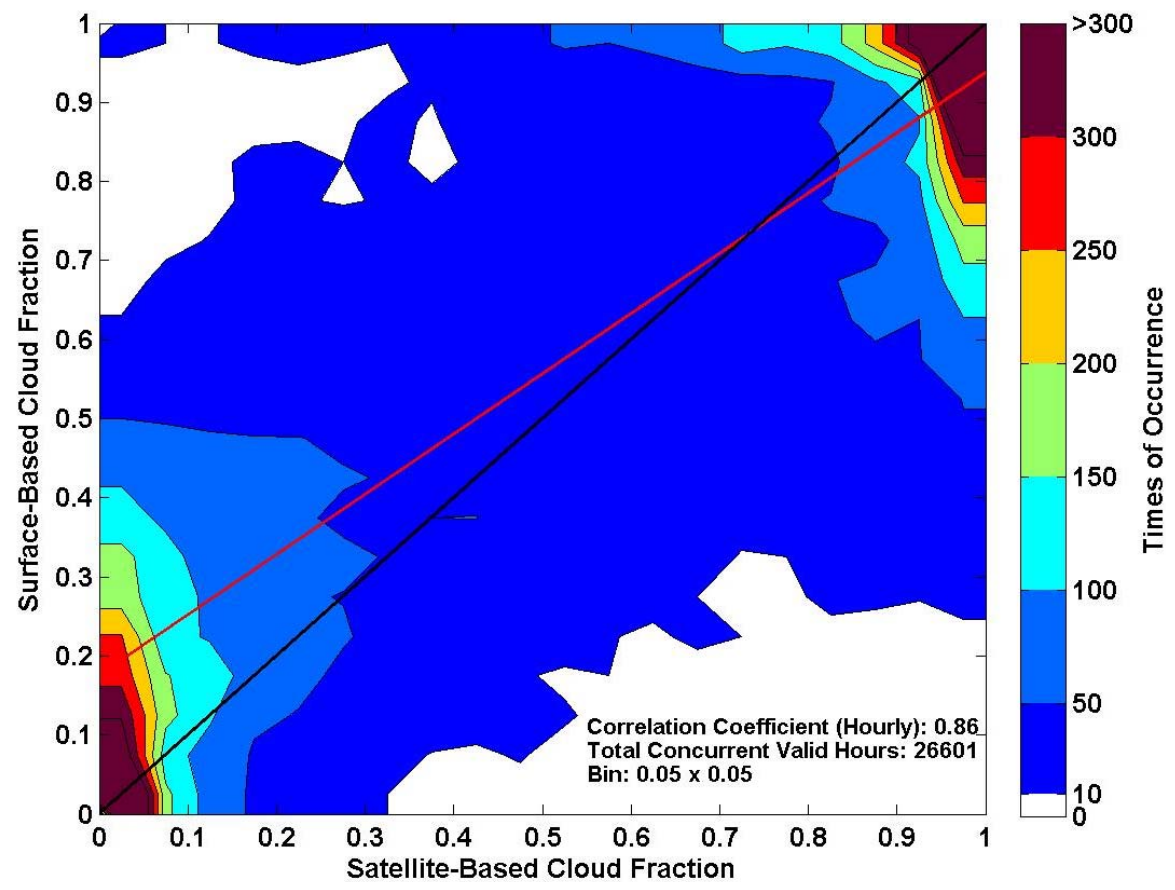

Fig. 2. Comparison between the surface-based and satellite-based cloud fractions. The red line denotes the linear fit to all the data points while the black diagonal line shows the perfect match as a reference.

line of regression. The former emphasizes the points of the most frequent occurrence whereas the latter emphasizes the mean. The two only agrees perfectly with each other when the sampling size is infinitely large and the scatter/noise is completely random, a condition rarely met in reality.

Because cloud fraction is used as an input in estimating both surface-based and satellite-based cloud albedo, an error in cloud fraction will result in a compensating error in the corresponding retrieval of cloud albedo. To examine the possibility of any compensating errors, Fig. 2 compares the cloud fractions derived from coincident surface-based and satellite measurements. Evidently, the surface-based and satellite-based cloud fractions exhibit better agreement compared to cloud albedo, with a correlation coefficient of 0.86 . Cloud fraction exhibits two clusters of occurrence similar to cloud albedo: one around low cloud fraction and the other around high cloud fraction. Together with Fig. 1, the results suggest frequent occurrences of scattered shallow clouds and near-overcast thick clouds. Such U-shaped behaviors have been reported in other studies (Hogan et al., 2001). It is interesting to note that based on the linear fit, surface-based cloud fraction is slightly lower than the satellite counterpart near overcast conditions, implying some degree of compensating errors between the surface-based cloud albedo and surface-based cloud fraction. However, a further inspection of the joint occurrence suggests that the compensating errors, if any, are negligibly small. This conclusion is further substantiated by Fig. 3, which compares the differences in cloud albedo and cloud fraction between surface and satellite mea- surements. The ellipsoid-like contours suggest that the two differences are virtually independent of each other. The difference in cloud fraction centers at 0.02 with a standard deviation of 0.20 ; the difference in cloud albedo centers at 0.09 with a standard deviation of 0.18 . These values are remarkable considering the different measurement systems and high hourly temporal resolutions.

\subsection{Further analysis}

As stated earlier in Sect. 2, the expression for estimating cloud albedo from surface-based radiation measurements is formulated on several assumptions, including a single-layer cloud, neglect of surface albedo and multiple surface-cloud reflections, and neglect of absorption by clouds and absorbing gases such as ozone and water vapor. This section serves to analyze and dissect the possible effects of these factors on the discrepancy between the surface-based and satellitebased cloud albedo.

\subsubsection{Effect of multilayer clouds}

Figure 1 shows all the coincident hourly data points with both measured cloud fractions $>0$, without differentiation of cloud layer structure. To quantify the effect of multilayer clouds, we partition the data into single-layer and multiple layer clouds based on another ARM VAP - Active Remote Sensing of CLouds (ARSCL, Clothiaux et al., 2000). By integrating measurements of different remote sensors (e.g., 


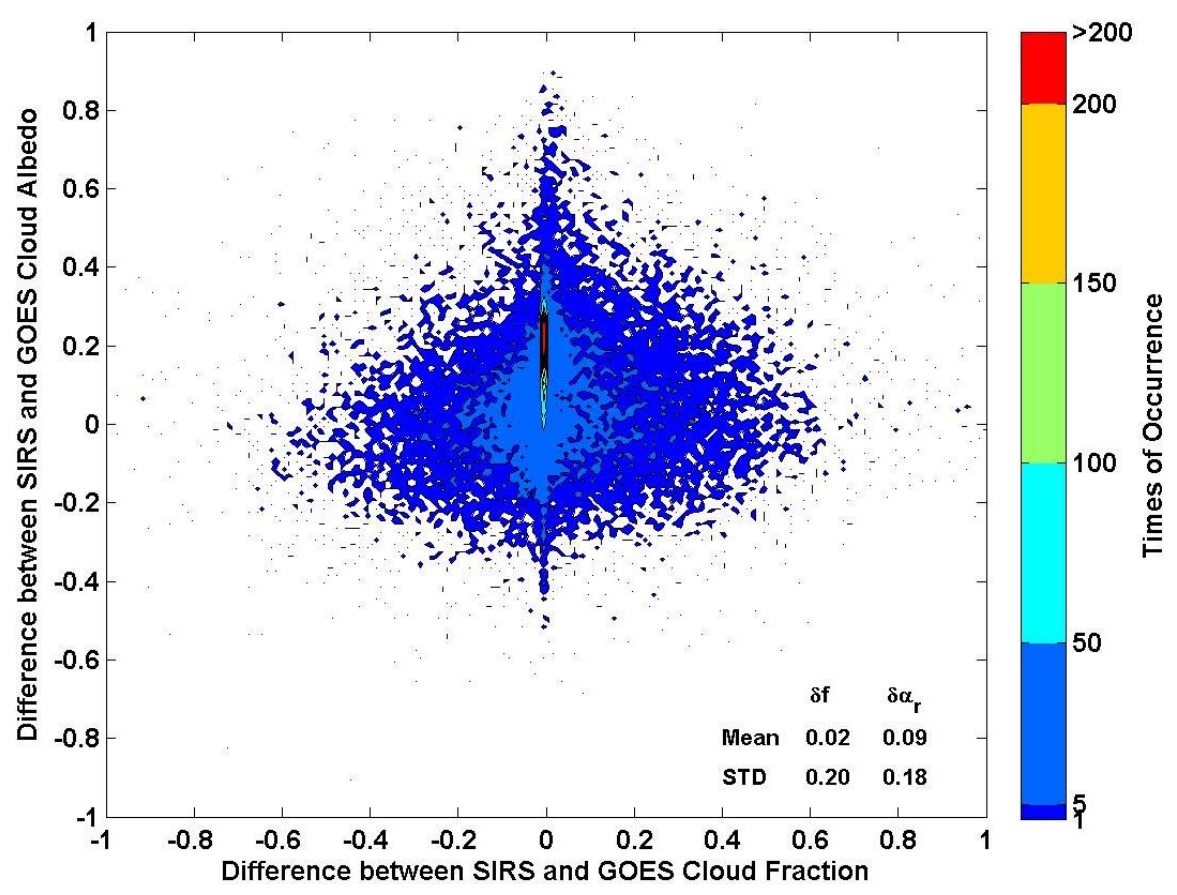

Fig. 3. Joint frequency distribution of the differences in cloud albedo and cloud fraction. The acronym STD denotes the standard deviation.

cloud radar, lidar and ceilometers), ARSCL provides heighttime distribution of cloud occurrence with $10 \mathrm{~s}$ temporal and $45 \mathrm{~m}$ vertical resolutions, as exemplified by Fig. 4. To obtain the best set of single-layer clouds, we apply the strictest possible criteria to identify the single-layer clouds. Briefly, at each height ( $45 \mathrm{~m}$ resolution) in the ARSCL profile, the presence or absence of clouds is determined, and the binary profile, then, of cloudy and clear levels, is examined to determine the layer structure. A layer is defined as a continuous, in the vertical, group of cloudy (or clear) levels. Each profile is then defined as clear, single- or multi-layer clouds. For each fifteen minute interval (the SIRS data resolution), then, the percentage of $10 \mathrm{~s}$ ARSCL profiles found to be clear, have single-layer clouds or have multilayer clouds is calculated. Figure 5 shows an example of this classification for a single 45 min time interval with three distinct time periods. The first period is dominated by single-layer clouds, followed by multi-layer clouds. The second time interval finds multilayered cloud about $60 \%$ of time, with very little single-layer clouds and some clear sky. The final time interval is dominated by single-layer clouds, with the remaining as clear sky.

To quantify the impact of multilayer clouds on the surfacebased cloud albedo, Fig. 6 compares the cloud albedo calculated from satellite-based and surface-based measurements for four different scenarios: all single-layer clouds, $75 \%$ single-layer clouds, $55 \%$ single-layer clouds, and $25 \%$ single-layer clouds. Clear-sky intervals are not considered in calculation of the percentage. Two points are evident together with Fig. 1. First, both the correlations and fitting curves do not change much from the scenario of
$100 \%$ single-layer clouds to those including all the multilayer clouds. This lack of dependence on single-layer cloud percentage supports the relaxation of the pure single-layer cloud assumption to an effective single-layer cloud assumption mentioned earlier. The other possibility is that the cloud layer structure affects surface-based and satellite-based retrievals similarly. Regardless of the specific reasons, for multilayer clouds, retrieved cloud albedo and cloud fraction represent some "effective" values, and depend likely on the structure of vertical cloud overlap as well. A brief discussion on this topic is given in the Appendix; more detailed investigation is beyond the scope of this paper. Second, the cluster around the satellite-based cloud albedo of $\sim 0.25$ disappears gradually with increasing percentage of single-layer clouds, suggesting that this cluster is likely related to multilayer structure. Plausible candidates causing this cluster are small cumuli and/or cloud edges, as both may be identified as multilayer clouds by the strict classification method used. These shallow clouds can enhance downwelling diffuse radiation and thus lead to apparent smaller cloud albedo. More subtle investigation is needed to confirm this speculation.

\subsubsection{Effect of surface albedo and multiple reflections}

Another factor that may affect the surface-based cloud albedo is the surface albedo and multiple reflections between clouds and surface ignored in the derivation of Eq. (6). To examine this issue, we use the simple model of multiple reflection presented by Wisocombe (1973). Based on Wiscombe (1973) and ignoring cloud absorption, we can obtain 


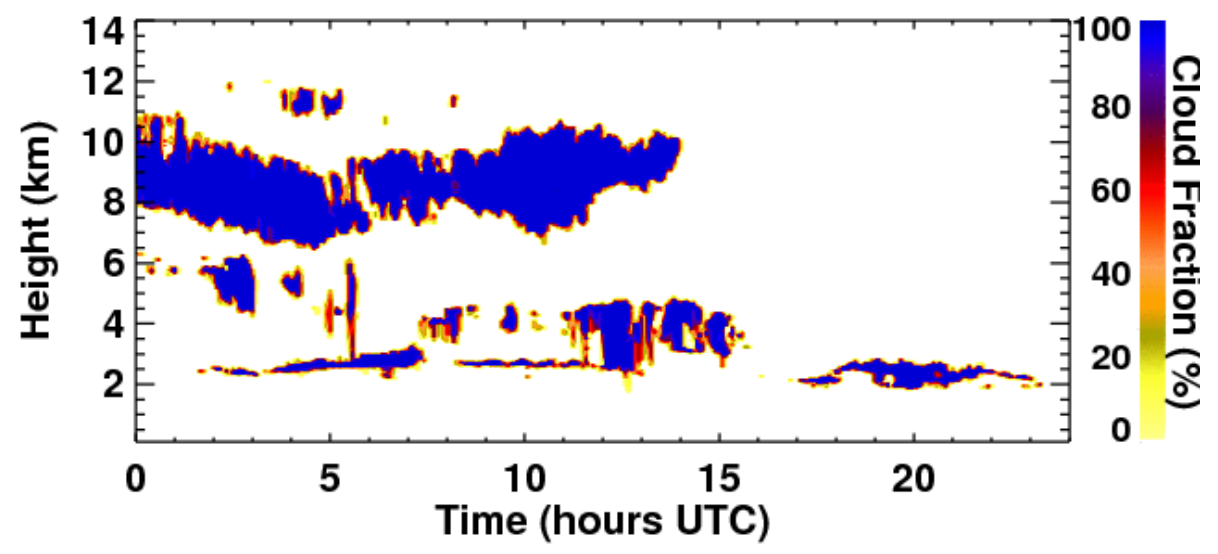

Fig. 4. An example of a time series of the ARSCL profile on 21 May 2003 at SGP. Note that the "cloud fraction" is actually referred to the frequency of occurrence, but is used here to avoid potential confusion with "times of occurrence" of Figs. 1-3.
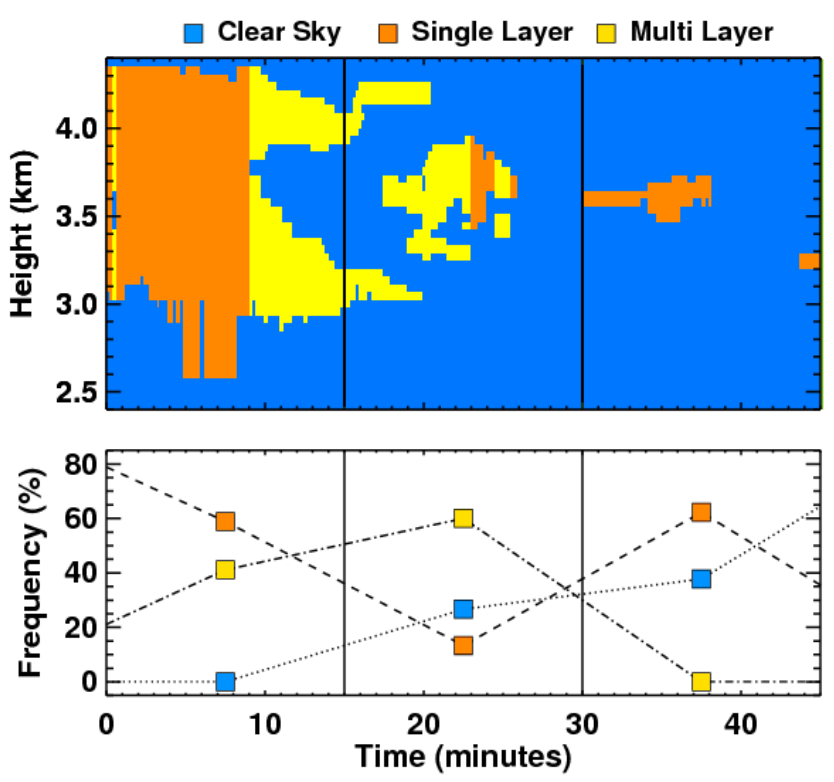

Fig. 5. An illustration of the classification of cloud layer structures. It is zoom-in snapshot of the period of 15:00-15:45 UTC of the example shown in Fig. 4.

the following expression

$\frac{\alpha_{\mathrm{cld}}^{\mathrm{SRF}}}{f}=\left(1-\alpha_{\mathrm{srf}}\right) \alpha_{\mathrm{r}}+\alpha_{\mathrm{srf}} \alpha_{\mathrm{r}}^{2}$

Equation (8) is evidently a generalization of Eq. (6) because it reduces to Eq. (6) when the surface albedo is zero. For clarity, we use $\alpha_{\mathrm{r}}$ and $\alpha_{\mathrm{r} 0}$ to denote the cloud albedo derived from Eqs. (8) and (6), respectively, wherever there may be confusion. Solving Eq. (8) for $\alpha_{\mathrm{r}}$ leads to

$\alpha_{\mathrm{r}}=\frac{\sqrt{\left(\left(1-\alpha_{\mathrm{srf}}\right)^{2}+4 \alpha_{\mathrm{srf}} \alpha_{\mathrm{r} 0}\right)}-\left(1-\alpha_{\mathrm{srf}}\right)}{2 \alpha_{\mathrm{srf}}}$.
A simple manipulation of Eq. (8) yields the expression for the difference given by

$\Delta=\alpha_{\mathrm{r}}-\alpha_{\mathrm{r} 0}=\alpha_{\text {srf }}\left(\alpha_{\mathrm{r}}-\alpha_{\mathrm{r}}^{2}\right) \geq 0$.

Equation (10) reveals that consideration of surface albedo and associated multiple reflections will increase the estimated cloud albedo. Figure 7 shows the difference as obtained from Eq. (10) for different values of surface albedo. An extreme value of analysis of Eq. (10) reveals that the maximum difference occurs at $\alpha_{\mathrm{r}}=0.5$ and equals to $0.25 \alpha_{\text {srf }}$, as shown in Fig. 7.

Surface albedo has also been measured by the SIRS system at SGP and provided in the SIRS VAP. An examination of these measurements indicates that surface albedo rarely exceed 0.3 (figure not shown here). Based on the values of surface albedo and the results shown in Fig. 7, it is unlikely that neglect of surface albedo and multiple reflections is the main factor for the discrepancy between the surface-based and satellite-based cloud albedo. This is further substantiated by Fig. 8, which compares the surface-based cloud albedo corrected for the effect of surface albedo and multiple reflections to the satellite-based cloud albedo.

\subsubsection{Effect of absorption associated with clouds}

The preceding analysis indicates that although errors in cloud fraction, cloud-layer structure, surface albedo and multiple reflections between surface and clouds may somewhat affect the estimation of surface-based cloud albedo, their effects are unlikely the main culprits responsible for the discrepancy between surface-based and satellite-based cloud albedo shown in Fig. 1. Another factor ignored in estimating cloud albedo from surface radiation measurements is the absorption by clouds and absorbing gases such as ozone and water vapor. Without having quantitative expressions to account for such individual absorbing effects, we seek to infer a parameter that lumps all the unknown factors together as follows. 


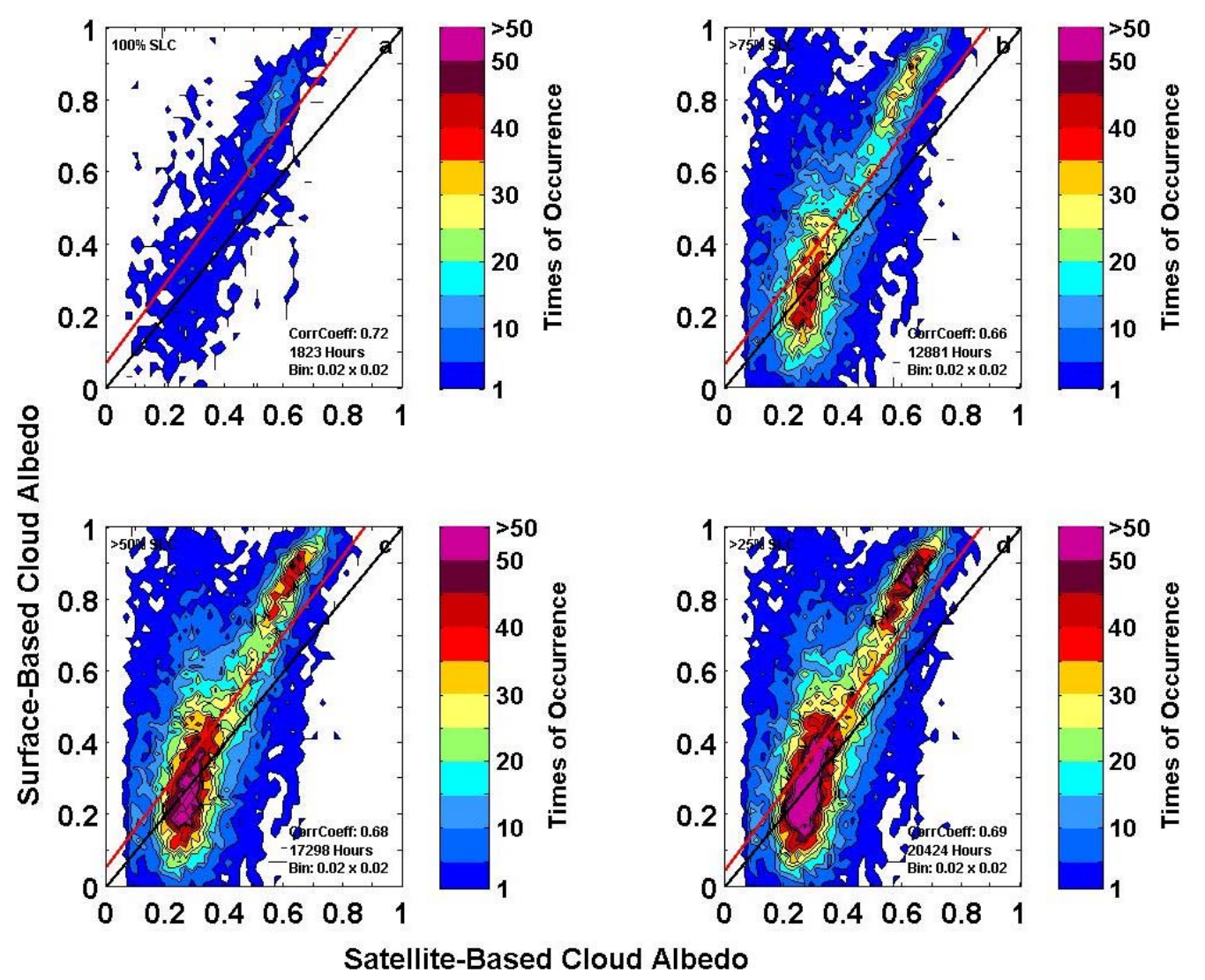

Fig. 6. Same as Fig. 1, except that each plot represents different percentage of the occurrence of single layer clouds.

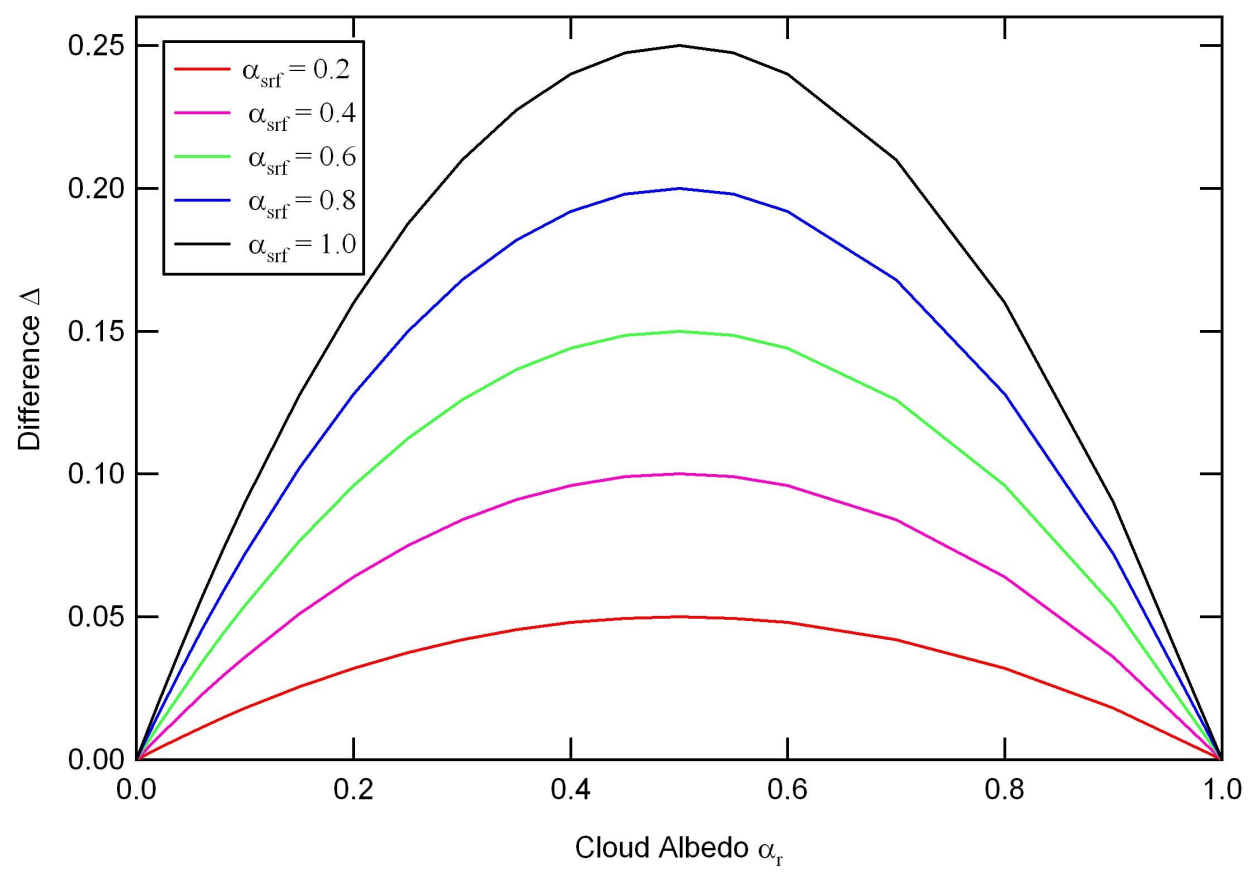

Fig. 7. Dependence of the difference $\Delta$ on cloud albedo for different values of surface albedo. 


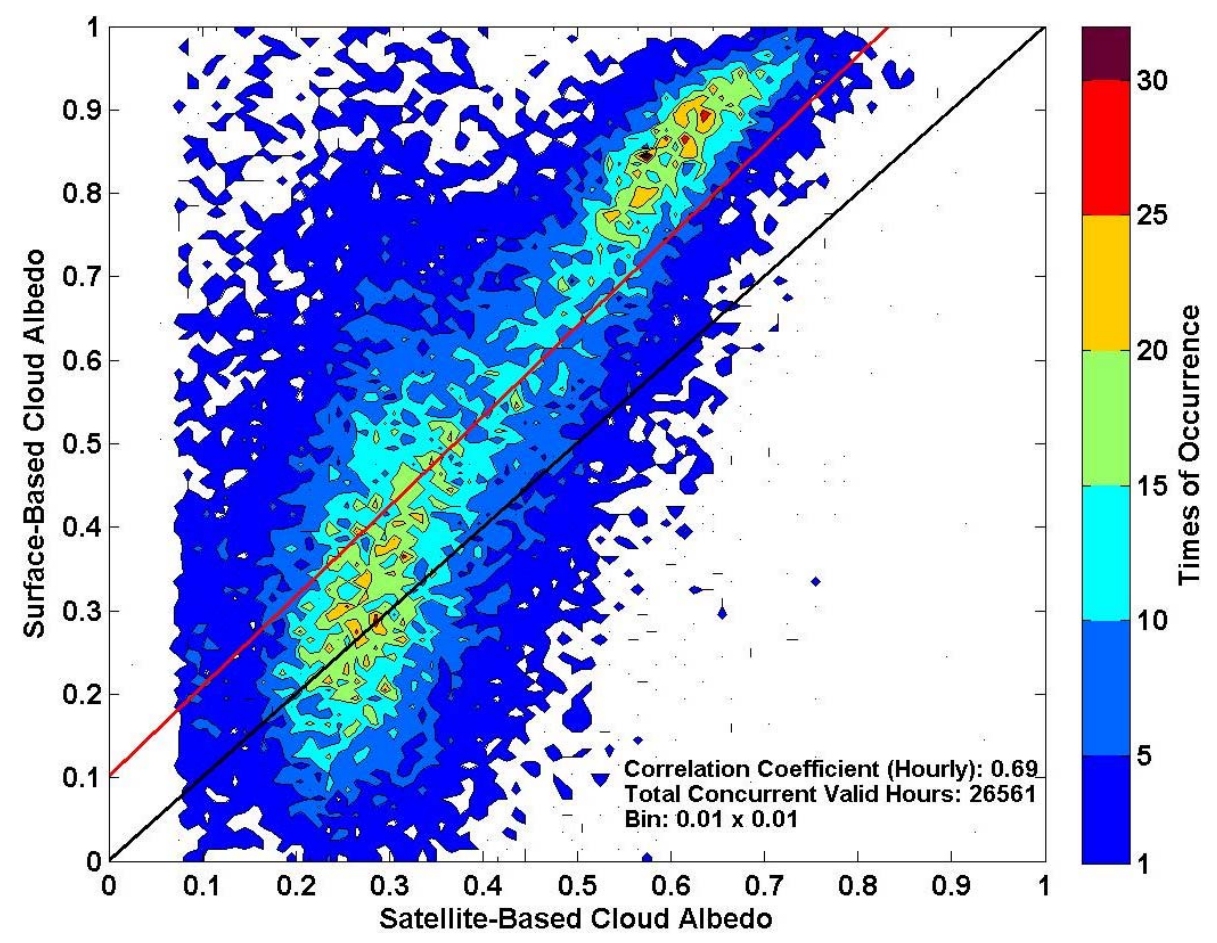

Fig. 8. Same as Fig. 1, except that the vertical axis is the surface-based cloud albedo corrected for the effect of surface albedo and multiple reflections. Note that the total number of points (26561) is less than 26601 in Fig. 1 due to some missing data on surface albedo.

It has been known that cloud absorptance is proportional to cloud albedo (Gautier and Landsfeld, 1997). Following this, we assume the unknown collective parameter, denoted by $x$, satisfies

$\alpha_{\mathrm{SIRS}}-x \alpha_{\mathrm{SIRS}}=\alpha_{\mathrm{GOES}}$,

where the subscript SIRS and GOES denote surface-based and satellite-based albedo, respectively. Therefore, we can infer $x$ from estimates of surface-based and satellite-based albedo using

$x=\frac{\alpha_{\mathrm{SIRS}}-\alpha_{\mathrm{GOES}}}{\alpha_{\mathrm{SIRS}}}$.

Equation (11b) indicates that aside from being a correction factor, $x$ represents the relative difference between surfacebased and satellite-based cloud albedos as well.

Figure 9 shows the parameter $x$ as a function of surfacebased cloud albedo. On average $x$ increases from negative values to $\sim 0.28$ as the surface-based cloud albedo increases from 0 to $\sim 0.5$, and levels off after that. The negative value of $x$ arises likely from the enhancement of downward diffuse radiation by shallow clouds while the dependence of $x$ on cloud albedo after cloud albedo $>0.3$ seems qualitatively consistent with cloud-related absorption. Quantitatively, the value 0.28 is much larger than the value of 0.07 used in Gautier and Landsfeld (1997); but the range of implied absorptance (from 0.05 to 0.3 ) is within the range of both previous observations (Hayasaka et al., 1995) and modeling studies
(Chiu et al., 2004). Hayasaka et al. (1995) also reported situations scattering from cloud edges may lead to apparent negative cloud absorptance. The issues of enhanced diffuse radiation and absorption associated with clouds are worth further investigation but beyond the scope of this paper. One can use the fitting equation shown in the figure to account for these effects before a rigorous theoretical formulation is established.

More information on the parameter $x$ can be obtained by examining its relationship to cloud fraction (Fig. 10). On average, $x$ first decreases from $\sim 0.5$ to $\sim-0.04$ when cloud fraction increases to $\sim 0.2$, slightly decreases with cloud fraction between 0.2 and 0.8 , and then increases with further increasing cloud fraction. The increase of $x$ with decreasing cloud fraction at low cloud fraction may arise from problems of retrieval accuracy and/or identification of clear-sky conditions while the increase of $x$ with increasing cloud fraction at high cloud fraction may be related to cloud absorption discussed earlier. As expected, the points in Fig. 10 are more scattered than those in Fig. 9. A comparison inspection of Figs. 9 and 10 further reveals that the clusters at both ends correspond with cases having similar cloud fraction but different values of cloud albedo.

\subsubsection{Other possible factors}

In addition to the factors that are explicitly assumed in the formulation and examined above, other potential factors may 


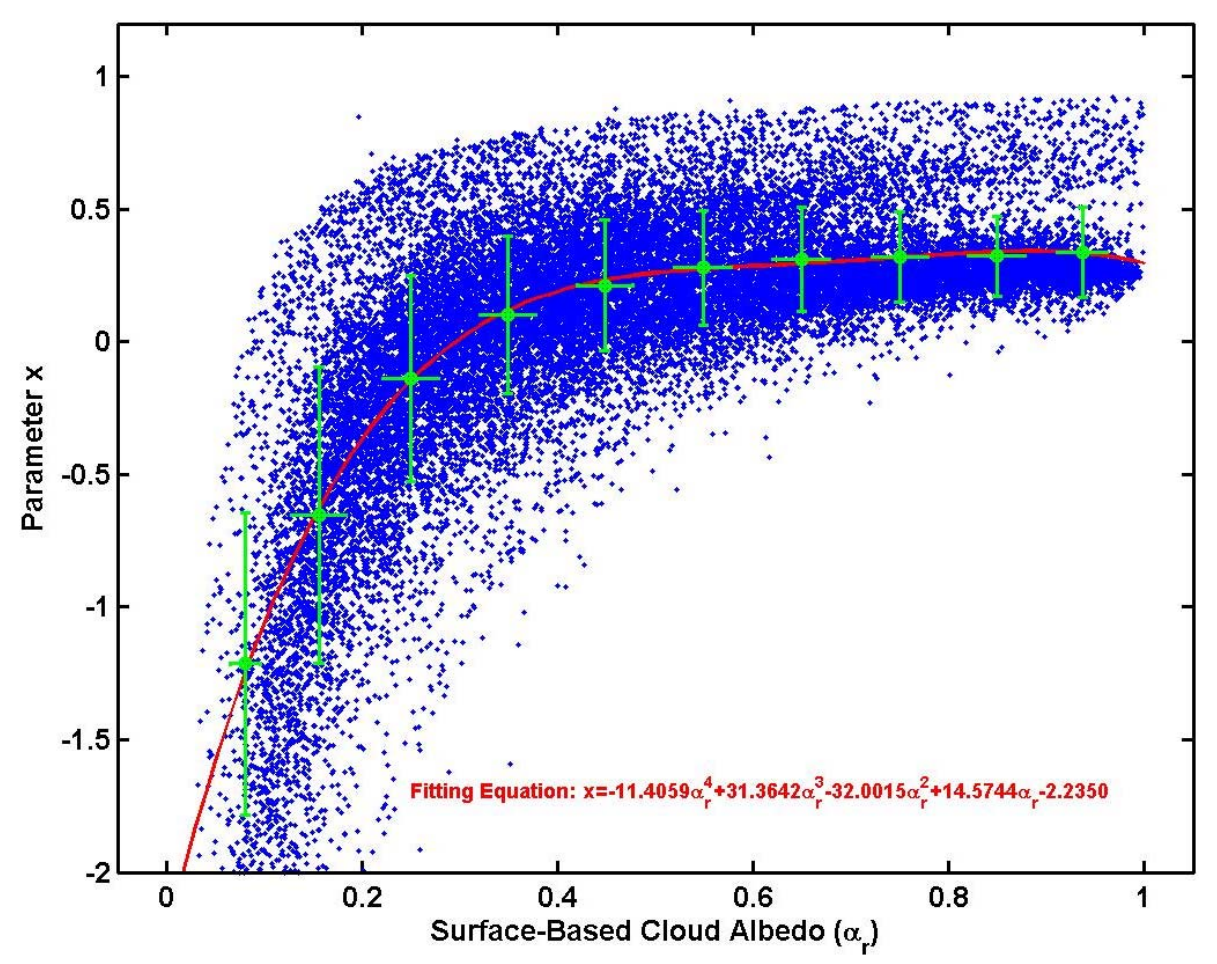

Fig. 9. The parameter $x$ as a function of surface-based cloud albedo. The red curve is the fit as described by the equation; the green dot and vertical lines are the average and corresponding \pm standard deviation, respectively. The data points with $x<-2$ are discarded in the analysis due to their rare and unphysical occurrences.

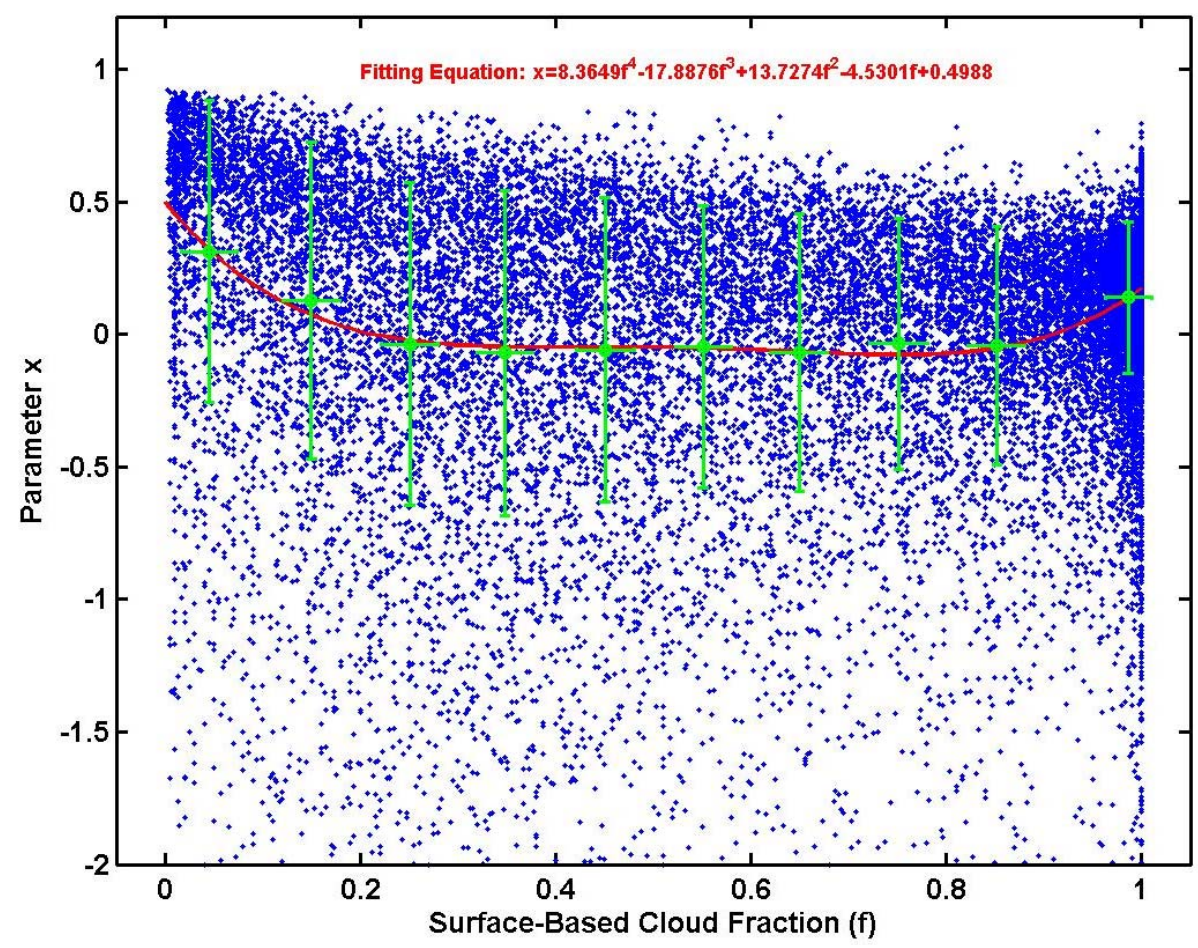

Fig. 10. Same as Fig. 9, except that it shows the parameter $x$ as a function of surface-based cloud fraction. 

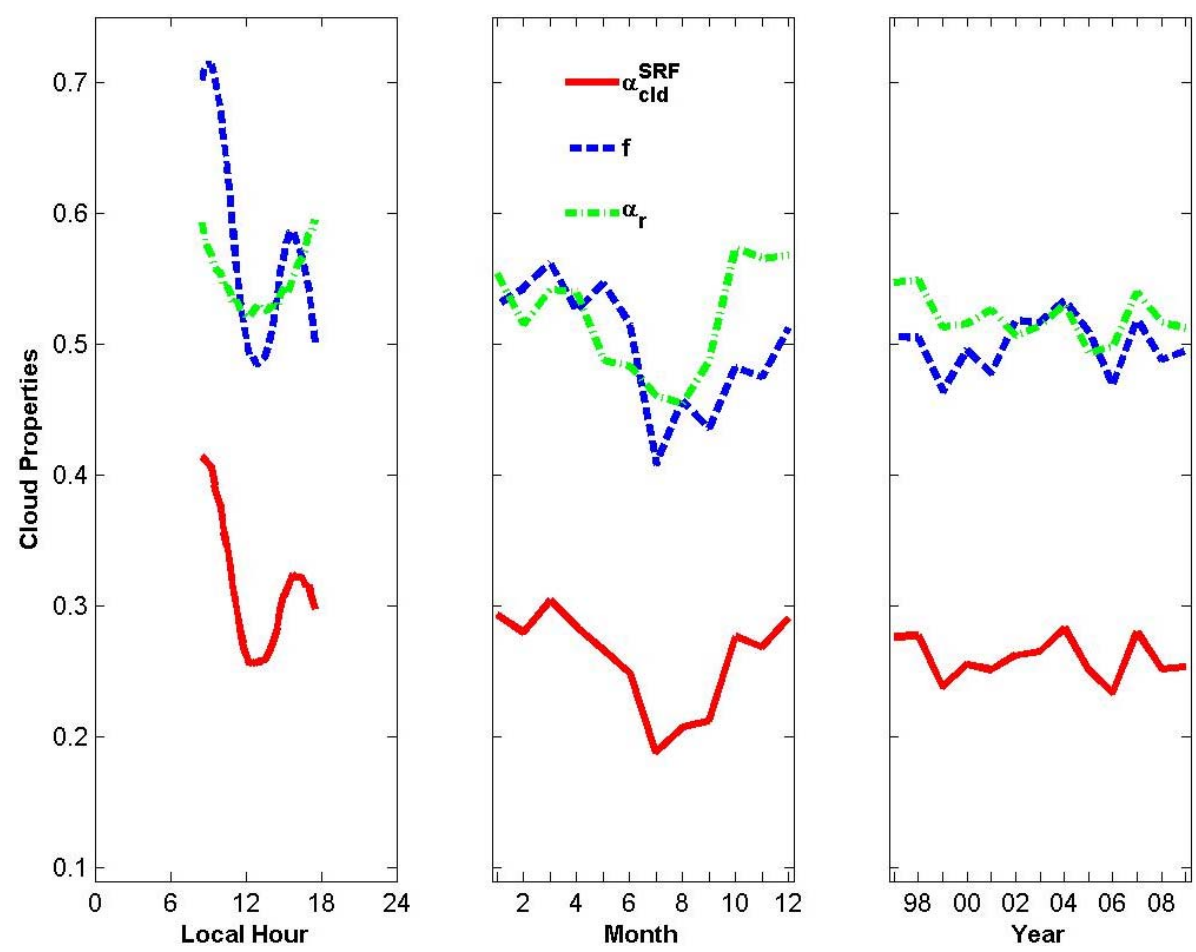

Fig. 11. Diurnal (left), annual (middle) and interannual (right) variations of the relative surface shortwave cloud radiative forcing (red), cloud fraction (blue) and cloud albedo (green).

affect the results as well. First, separating the atmosphere into clear and cloudy portions is a basic premise for both surface-based and satellite-based retrievals. Calculation of relative CRF also requires estimation of clear-sky downwelling shortwave radiation. Although the criteria for identification of clear sky in both surface and satellite observations have been rigorously tested and validated, they may cause some uncertainties when cloud fraction/cloud albedo are low and near the clear-cloudy boundary. The clear-cloudy separation is often fuzzy in presence of high aerosol loading and near cloud edges (Charlson et al., 2007; Koren et al., 2007; Tackett and Di Girolamo, 2009; Varnai and Marshak, 2011). The large scatter at low cloud albedo may be related to the clear-sky identification. In addition, the two sampling platforms have different sampling principles and volumes; these inherent instrumental differences may also be responsible for the discrepancy. Finally, satellite and surface measurements may be biased toward high and low clouds, respectively. Note that our analysis of discrepancy is focused on the surface-based measurements, although one should be aware that satellite retrievals are fraught with various uncertainties as well.

\section{Multiscale variations}

Equation (5c) clearly reveals that the uncertainty in reported values of CRF simulated by different GCMs may arise from inadequate treatments of both cloud albedo and cloud fraction. Systematic examination of $\alpha_{\text {cld }}^{\mathrm{SRF}}$ only started very recently by Betts and his coworkers by using indirect satellite surface radiation measurements. This section reports the results from the long-term (1997-2009) surface-based, highresolution ARM measurements collected at the SGP site. In our analysis, the 15-min data are further aggregated into hourly, monthly and yearly averages to examine the diurnal (Fig. 11a), annual (Fig. 11b) and interannual variations (Fig. 10c) of $\alpha_{\mathrm{cld}}^{\mathrm{SRF}}, f$, and $\alpha_{\mathrm{r}}$. A few points can be drawn from these figures. First, all the three quantities exhibit diurnal and annual variations. Although the diurnal cycle is not complete due to the need for absent downwelling shortwave radiation flux measurements at nighttime, the minima around local noon are obvious, with $0.26,0.48$ and 0.52 for $\alpha_{\text {cld }}^{\mathrm{SRF}}, f$ and $\alpha_{\mathrm{r}}$, respectively. Two maxima appear for $\alpha_{\mathrm{cld}}^{\mathrm{SRF}}$ and $f$. The first occurs in local morning $(0.41,0.71$ and 0.59 for $\alpha_{\text {cld }}^{\mathrm{SRF}}, f$ and $\left.\alpha_{\mathrm{r}}\right)$ and the second in local afternoon $(0.32,0.59$ and 0.60 for $\alpha_{\text {cld }}^{\mathrm{SRF}}, f$ and $\alpha_{\mathrm{r}}$ ). On monthly scales, the summertime minima are evident, with $\alpha_{\text {cld }}^{\mathrm{SRF}}=0.19$ and $f=0.41$ in July, and $\alpha_{\mathrm{r}}=0.45$ in August. The maxima for $\alpha_{\text {cld }}^{\mathrm{SRF}}(0.30)$ and $f(0.56)$ occur in March while for $\alpha_{\mathrm{r}}(0.57)$ in October. The diurnal pattern of cloud fraction (i.e., morning maximum and noon minimum) is consistent with the results obtained by Lazarus et al. (2000) from analyzing 1-yr cloud amount data from measurements of micro pulse lidars and ceilometers, 10-yr cloud fraction data from Edited Cloud Report, and 8-yr 


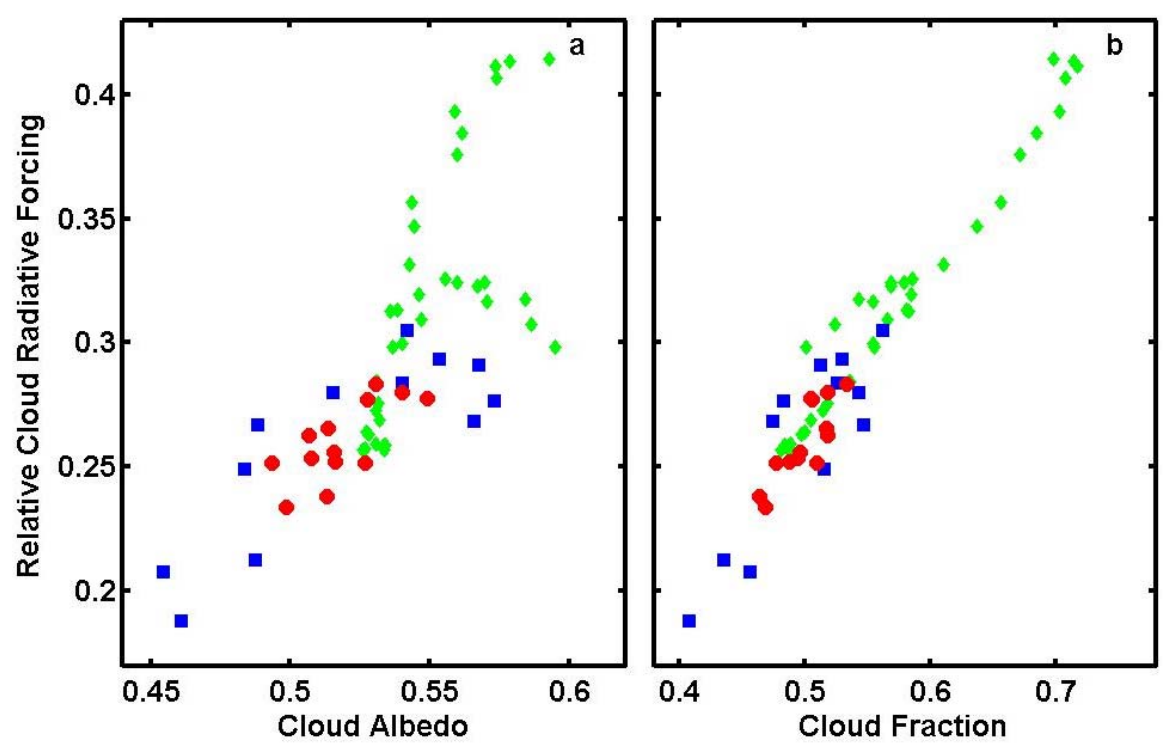

Fig. 12. Scatter plots showing correlation between the relative surface shortwave cloud radiative forcing and cloud fraction (a), and cloud albedo (b). The colors of red, green and blue denote hourly, monthly, and annual averages, respectively.

ISCCP cloud fraction data. This minimum near-noon cloud fraction characteristic is also similar to results from other researches for other locations (Considine et al., 1997). However, the diurnal pattern of cloud fraction differs somewhat from the flat pattern presented in Dong et al. (2006), The different datasets used may be a reason for the diaparity; Dong et al. (2006) used data derived from cloud-radar and lidar measurements. More studies are needed to pinpoint the exact reasons. The annual-cycle pattern of cloud fraction (i.e., wintertime maximum and summertime minimum) is consistent with those obtained by previous studies (e.g., Lazarus et al., 2000; Dong et al., 2006; Kollias et al., 2007). The annual variation of $\alpha_{\mathrm{cld}}^{\mathrm{SRF}}$ is similar to that observed in other continental areas such as Amazon and Missouri (Betts, 2007, 2009; Betts et al., 2009). Second, the three quantities exhibit relatively less interannual variation; with the $13 \mathrm{yr}$ averages of $\alpha_{\mathrm{cld}}^{\mathrm{SRF}}, f$ and $\alpha_{\mathrm{r}}$ are $0.26,0.50$ and 0.52 , respectively. Finally, although the three quantities tend to vary largely in phase, the variation of $\alpha_{\mathrm{cld}}^{\mathrm{SRF}}$ is correlated more with $f$ than with $\alpha_{\mathrm{r}}$. This can be seen more clearly in Fig. 12a, b. The higher correlation with $f$ suggests that the variation of $\alpha_{\text {cld }}^{\mathrm{SRF}}$ is driven more by that of $f$ than by that of $\alpha_{\mathrm{r}}$, which, together with Eq. (5c),.implies that $f$ varies slightly more compared to $\alpha_{\mathrm{r}}$. The positively-correlated relationship between $\alpha_{\mathrm{cld}}^{\mathrm{SRF}}$ and $f$ was also found in Betts et al. (2009).

\section{Concluding remarks}

An analytical relationship between the relative surface shortwave cloud radiative forcing, cloud fraction and cloud albedo is derived theoretically. The analytical relationship not only reveals that the relative surface shortwave cloud radiative forcing is approximately a product of cloud fraction and cloud albedo, it also suggests a new approach to inferring cloud albedo from surface-based concurrent measurements of surface downwelling shortwave radiative fluxes and cloud fraction. This new surface-based approach is applied to the long-term measurements collected at the ARM SGP site, and the surface-based estimates of cloud albedo compare favorably with those obtained from the concurrent GOES satellite data.

The assumptions underlying the formulation are examined for their potential effects on the estimate of cloud albedo with the surface-based method, including single-layer clouds, neglect of surface albedo and multiple reflections between surface and clouds, and absorption associated with clouds. The results suggest that multilayer clouds, surface albedo, and multiple reflections are unlikely the main reasons for the discrepancy between surface-based and satellite-based cloud albedo. Possible candidates are the enhanced downward diffuse radiation in presence of scattered shallow clouds when cloud albedo is small ( $<\sim 0.3)$, and cloud-associated absorption when cloud albedo is larger than $\sim 0.3$. More study is needed to substantiate this finding.

The decade-long high resolution data are examined to discern their multiscale (diurnal, annual and interannual) variations and covariations of the relative surface shortwave cloud radiative forcing, cloud fraction and cloud albedo. The diurnal variations of all the three quantities exhibit a strong minimum around local noon. The annual variations exhibit a minimum in summertime and a maximum in wintertime. There exhibits some smaller year-to-year variability in all the three quantities, but no obvious trend can be discerned. The variation of relative surface shortwave cloud radiative forcing 
follows cloud fraction more closely than cloud albedo.

This study clearly demonstrates and reinforces the usefulness of the relative cloud radiative forcing in isolating the cloud radiative effect from non-cloud factors, and further relating it to cloud fraction and cloud albedo. Nevertheless, the study is just a beginning, and much remains to be done. First, ARM has supported other SGP-like sites in different climatic regimes. Application of the approaches presented here to these sites will test the applicability of the presented approaches in different climatic regimes. Furthermore, increasing number of surface sites like the ARM SGP site has been established to measure surface radiation around the world such as the Baseline Surface Radiation Network (BSRN, Ohmura et al., 1998). Further application of the new approaches to these measurements will provide a much needed global data set for cloud albedo based on radiation measurements at surface. Second, model evaluation against observations is essential to identifying model deficiencies, and this important endeavor demands long-term data of high quality and resolution. The surface-based data thus obtained will be valuable and complementary to the widely used satellite measurements. The analytical formulation should be useful in diagnosis of parameterization deficiencies as well. Third, the focus of this paper is on solar radiation at surface, similar ideas are expected applicable to solar radiation at TOA and terrestrial infrared radiation measurements. Fourth, to capture the physical essence with simple analytical expressions, the theoretical framework is formulated to represent the first order effect under a few simplifying assumptions. It is desirable to confirm the analytical formulation with a more rigorous model. Also, the present methodology estimates cloud albedo and cloud fraction separately. Although the method appears to work well here in general, it suffers from the potential problem of compensating errors between retrievals of cloud fraction and cloud albedo and the need to identify overcast conditions separately. A methodology for simultaneous retrievals of both cloud fraction and cloud albedo is more desirable because cloud fraction and cloud albedo likely affect total and diffuse radiations together and concurrently. Coinvestigation of cloud albedo and cloud fraction makes more physical sense as well. Taking into account cloud 3-D effect and horizontal photon transport may be necessary as well, especially for multilayer clouds and small cumulus clouds with low cloud albedo and cloud fraction. Finally, further understanding and improving the retrieval techniques demand uncertainty estimates of all the measurements involved. Uncertainty quantification of cloud fraction and cloud albedo is needed for model evaluation as well, and is worthy pursuing in the future.

\section{Appendix A}

\section{Effective single-layer model and cloud overlap}

When there are clouds of $N$ layers with each layer characterized by cloud albedo $\alpha_{\mathrm{r} i}$ and cloud fraction $f_{i}(i=1, \ldots$, $N)$, the relative CRF can be expressed as

$\alpha_{\mathrm{cld}}^{\mathrm{SRF}}=\sum_{i=1}^{N} \alpha_{\mathrm{r} i} f_{i}$.

Similar expression has been used to study CRF for multilayer clouds (e.g., Ramanathan et al., 1989a). In terms of the corresponding effective cloud properties, Eq. (A1) can be rewritten as

$\alpha_{\mathrm{re}} f_{e}=\sum_{i=1}^{N} \alpha_{\mathrm{r} i} f_{i}$,

or,

$\alpha_{\mathrm{re}}=\frac{\sum_{i=1}^{N} \alpha_{\mathrm{ri}} f_{i},}{f_{e}}$,

where the subscript " $e$ " represents the corresponding effective property. The effective cloud fraction $f_{e}$ depends on the vertical cloud overlap, and several overlap models have been proposed (Hogan and Illingworth, 2000). An additional constraint on the effective single-layer cloud is that both effective cloud fraction and effective cloud albedo are no greater than one. Equation (A3) indicates that like $f_{e}$, the effective cloud albedo also depends on cloud overlap assumptions. Take the extreme maximum (minimum) overlap as an example, multilayer clouds tend to have minimum (maximum) effective cloud fraction but maximum (minimum) effective cloud albedo.

Acknowledgements. This work is supported by the Climate System Modeling (ESM) via the FASTER project (www.bnl.gov/esm) and Atmospheric Science Research (ASR) programs of the US Department of Energy. The data are obtained from the ARM website (http://www.archive.arm.gov/armlogin/login.jsp). Peter H. Daum read the manuscript and provides valuable comments. Discussion with Drs. Wuyin Lin, Andy Vogelmann and Warren Wiscombe at the Brookhaven National Laboratory are appreciated. The comments from the anonymous reviewers help improve the manuscript.

Edited by: J. Quaas

\section{References}

Ackerman, T. P. and Stokes, G. M.: The Atmospheric Radiation Measurement Program, Phys. Today, January 2003, 38-44, 2003.

Arakawa, A.: Modeling clouds and cloud processes for use in climate model. The Physical Basis of Climate and Climate Modeling, GARP Publication Series, WMO, 16, 183-197, 1975. 
Arking, A.: The radiative effects of clouds and their impact on climate, B. Am. Meteorol. Soc, 71, 795-813, 1991.

Arking, A.: The influence of clouds and water vapor on atmospheric absorption, Geophys. Res. Lett, 26, 2729-2732, 1999.

Bender, F. A.-M., Rodhe, H., Charlson, R. J., Ekman, A. M. L, and Loeb, N.: 22 views of the global albedo-comparison between 20 GCMs and two satellites, Tellus, 58A, 320-330, 2006.

Bender, F. A.-M., Charlson, R. J., Ekman, A. M. L., and Leahy, L. V.: Quantification of monthly mean regional scale albedo of stratiform clouds in satellite observations and GCMs, J. Appl. Meteorol. Clim., in press, http://journals.ametsoc.org/doi/abs/10. 1175/JAMC-D-11-049.1, 2011.

Betts, A. K.: Coupling of water vapor convergence, clouds, precipitation, and land-surface processes, J. Geophys. Res., 112, D10108, doi:10.1029/2006JD008191, 2007.

Betts, A. K.: Land-Surface-Atmosphere Coupling in Observations and Models, J. Adv. Model. Earth Syst., 1, 4, doi:10.3894/JAMES.2009.1.4, 2009.

Betts, A. K. and Viterbo, P.: Land-surface, boundary layer and cloud-field coupling over the south-western Amazon in ERA40, J. Geophys. Res., 110, D14108, doi:10.1029/2004JD005702, 2005.

Betts, A. K., Köhler, M., and Zhang, Y.: Comparison of river basin hydrometeorology in ERA-Interim and ERA-40 reanalyses with observations, J. Geophys. Res, 114, D02101, doi:10.1029/2008JD010761, 2009.

Bony, S. and Dufresn, J. E.: Marine boundary layer clouds at the heart of tropical cloud feedback uncertainties in climate models, Geophys. Res. Lett., 32, L20806, doi:10.1029/2005GL023851, 2005.

Bony, S., Colman, R., Kattsnov, V. M., Allan, R. P., Bretherton, C. S., Dufresne, J., Hall, A., Hallegatte, S., Holland, M. M., Ingram, W., Randall, D. A., Soden, B. J., Tselioudis, G., and Webb, M. J.: How well do we understand and evaluate climate change feedback processes?, J. Climate, 19, 3445-3482, 2006.

Cess, R. D.: Climate change: An appraisal of atmospheric feedback mechanisms employing zonal climatology, J. Atmos. Sci., 33, 1831-1843, 1976.

Cess, R. D. and Potter, G. L.: Exploratory studies of cloud radiative forcing with a general circulation model, Tellus, 39A, 460-473, 1987.

Cess, R., Zhang, M., Potter, G. L., Alekseev, V., Barker, H. W., Bony, S., Colman, R. A., Dazlich, D. A., Del Genio, A. D., Déqué, M., Dix, M. R., Dymnikov, V., Esch, M., Fowler, L. D., Fraser, J. R., Galin, V., Gates, W. L., Hack, J. J., Ingram, W. J., Kiehl, J. T., Kim, Y., Le Treut, H., Liang, X.-Z., McAvaney, B. J., Meleshko, V. P., Morcrette, J. J., Randall, D. A., Roeckner, E., Schlesinger, M. E., Sporyshev, P. V., Taylor, K. E., Timbal, B., Volodin, E. M., Wang, W., Wang, W. C., and Wetherald, R. T.: Comparison of the seasonal change in cloud-radiative forcing from atmospheric general circulation models and satellite observations, J. Geophys. Res., 102(D14), 16593-16603, 1997.

Cess, R. D., Zhang, M., Wielicki, B. A., Young, D. F., Zhou, X., and Nikitenko, Y.: The influence of the 1998 El Niño upon cloud radiative forcing over the Pacific warm pool, J. Climate, 14, 21292137, 2001.

Charlock, T. P. and Ramanathan, V.: The albedo field and cloud radiative forcing produced by a general circulation model with internally generated cloud optics, J. Atmos. Sci., 42, 1408-1429,
1985.

Charlson, R. J., Ackerman, A. S., Bender, F. A.-M., Anderson, T. L., and Liu, Z.: On the climate forcing consequences of the albedo continuum between cloudy and clear air, Tellus, 59, 715-727, 2007.

Chiu, J. Y. C, Marshak, A., and Wiscombe, W. J.: The effect of surface heterogeneity on cloud absorption estimates, Geophys. Res. Lett., 31, L15105, doi:10.1029/2004GL020104, 2004.

Clothiaux, E. E., Ackerman, T. P., Mace, G. G., Moran, K. P., Marchand, R. T., Miller, M. A., and Martner, B. E.: Objective determination of cloud heights and radar reflectivities using a combination of active sensors at the ARM CART sites, J. Appl. Meteorol., 39, 645-665, 2000.

Coakley, J. A. Jr. and Badwin, D. G.: Towards the objective analysis of clouds from satellite imagery data, J. Clim. Appl. Meteorol., 23, 1065-1099, 1984.

Coakley, J. A. Jr., Friedman, M. A., and Tahnk, W. R.: Retrieval of cloud properties for partly cloudy imager pixels, J. Atmos. Oceanic Technol., 22, 3-17, 2005.

Considine, G., Curry, J. A., and Wielicki, B.: Modeling cloud fraction and horizontal variability in marine boundary layer clouds, J. Geophys. Res., 102(D12), 13517-13525, 1997.

Dong, X., Xi, B., and Minnis, P.: A Climatology of Midlatitude Continental Clouds from the ARM SGP Central Facility. Part II: Cloud Fraction and Surface Radiative Forcing, J. Climate, 19(9), 1765-1783, 2006.

Ellis, J. S.: Cloudiness, the planetary radiation budget, and climate, Ph. D. thesis, Colorado State University, 129 pp., 1978.

Gautier, C. and Landsfeld, M.: Surface solar radiation flux and cloud radiative forcing for the Atmospheric Radiation Measurement (ARM) Sothern Great Plains (SGP): A satellite, surface observations, and radiative transfer model study, J. Atmos. Sci., 54, 1289-1307, 1997.

Griggs, M.: Aircraft measurements of albedo and absorption of stratus clouds, and surface albedos, J. Appl. Meteorol., 7, 1012$1017,1968$.

Harrison, E. F., Minnis, P., Barkstrom, B. R., Ramanathan, V., Cess, R. D., and Gibson, G. G.: Seasonal variation of cloud radiative forcing derived from the Earth Radiation Budget Experiment, J. Geophys. Res., 95, 18687-18703, 1990.

Hayasaka, T., Kikuchi, N., and Tanaka, M.: Absorption of solar radiation by stratocumulus clouds: aircraft measurements and theoretical calculation, J. Appl. Meteorol., 34, 1047-1055, 1995.

Hogan, R. J. and Illingworth, A. J.: Deriving cloud overlap statistics from radar, Q. J. Roy. Meteorol. Soc., 126, 2903-2909, 2000.

Hogan, R. J., Jakob, C., and Illingworth, A. J.: Comparison of ECMWF winter-season cloud fraction with radar-derived values, J. Appl. Meteorol., 40, 513-525, 2001.

Imre, D. G., Abramson, E. H, and Daum, P. H.: Quantifying cloudinduced shortwave adsorption: An examination of uncertainties and of recent arguments for large excess absorption, J. Appl. Meteorol., 35, 1991-2010, 1996.

Kollias, P., Tselioudis, G., and Albrecht, B. A.: Cloud climatology at the Southern Great Plains and the layer structure, drizzle, and atmospheric modes of contnental stratus, J. Geophys. Res., 112, D09116, doi:10.1029/2006JD007307, 2007.

Koren, I., Remer, L. A., Kaufman, Y. J., Rudich, Y., and Martins, J. V.: On the twilight zone between clouds and aerosols, Geophys. Res. Lett., 34, L08805, doi:10.1029/2007GL029253, 2007. 
Laszlo, I. and Pinker, R. T.: Shortwave cloud-radiative forcing at the top of the atmosphere, at the surface and of the atmospheric column as determined from ISCCP C1 data, J. Geophys. Res., 112(D2), 2703-2713, 1993.

Lazarus, S. M., Krueger, S. K., and Mace, G. G.: A cloud climatology of the Southern Great Pains ARM CART, J. Climate, 13, 1762-1775, 2000.

Li, Z. and Trishchenko, A. P.: Quantifying uncertainties in determining SW cloud radiative forcing and cloud absorption due to variability in atmospheric conditions, J. Atmos. Sci., 58, 376389, 2001.

Loeb, N. G., Wielicki, B. A., Rose, F. G., and Doellling, D. R.: Variability in global top-of-atmosphere shortwave radiation between 2000 and 2005, Geophys. Res. Lett., 34, L03704, doi:10.1029/2006GL028196, 2007.

Long, C. N. and Ackerman, T. P.: Identification of Clear Skies from Broadband Pyranometer Measurements and Calculation of Downwelling Shortwave Cloud Effects, J. Geophys. Res., 105(D12), 15609-15626, 2000.

Long, C. N, Ackerman, T. P., Gaustad, K. L., and Cole, J. N. S.: Estimation of fractional sky cover from broadband shortwave radiometer measurements, J. Geophys. Res. , 111, D11204, doi:10.1029/2005JD006475, 2006.

Mace, G. G. and Benson, S.: The Vertical Structure of Cloud Occurrence and Radiative Forcing at the SGP ARM Site as Revealed by 8 Years of Continuous Data, J. Climate, 21(11), 2591, doi:10.1175/2007JCLI1987.1, 2008.

Mace, G. G., Benson, S., Sonntag, K., Kato,, S., Min, Q., Minnis, P., Twohy, C., Poellot, M., Dong, X., Long, C., Zhang, Q., and Doelling, D.: Cloud radiative forcing at the Atmospheric Radiation Measurement Program Climate Research Facility, J. Geophys. Res., 111, D11S90, doi:10.1029/2005JD005921, 2006.

Minnis, P. and Smith Jr, W. L. : Cloud and radiative fields derived from GOES-8 during SUCCESS and the ARM-UAV Spring 1996 flight series, Geophys. Res. Lett., 25, 1113-1116, 1998.

Minnis, P., Nguyen, L., Palikonda, R., Heck, P. W., Spangenberg, D. A., Doelling, D. R., Ayers, J. K., Smith Jr, W. L., Khaiyer, M. M., Trepte, Q. Z., Avey, L. A., Chang, F.-L., Yost, C. R., Chee, T. L., and Sun-Mack, S.: Near-real time cloud retrievals from operational and research meteorological satellites, Proc. SPIE European Remote Sensing, Cardiff, Wales, IK, 15-18 September, 2008a.

Minnis, P., Trepte, Q. Z., Sun-Mack, S., Chen, Y., Doelling, D. R., Young, D. F., Spangenberg, D. A., Miller, W. F., Wielicki, B. A., Brown, R. R., Gibson, S. C., and Geier, E. B.: Cloud detection in non-polar regions from CERES using TRMM VIRS and Terra and Aqua MODIS data, IEEE T. Geosci. Remote Sens., 46, 3857-3884, 2008b.

Ohmura, A., Dutton, E. G., Forgan, B., Frohlich, C., Gilgen, H., Hegner, H., Heimo, A., Konig-Langlo, G., McArthur, B., Muller, G., Philipona, R., Pinker, R., Whitlock, C. H., Dehne, K., and Wild, M.: Baseline Surface Radiation Network (BSRN/WCRP): new precision radiaometry for climate research, Bull. Am. Meteorol. Soc., 79, 2115-2136, 1998.

O'Malley, M. S. and Duchon, C. E.: A daytime radiation and cloud climatology from time series of measured surface irradiance, 249-251, Proceedings of the ARM Annul Meeting, San Antonio, Texas, USA, 1996.

Palle, E., Goode, P. R., Yurchyshyn, V., Qiu, J., Hickey, J.,
Montanes-Rodriguez, P. P., Chu, M.-C., Kolbe, E., Brown, C. T., and Koonin, S. E.: Earthshine and the Earth's a;bedo: 2. Observations and simulations over 3 years, J. Geophys. Res., 108, D4710, doi:10.1029/2003JD003611, 2003.

Palle, E., Goode, P. R., and Montanes-Rodriguez, P.: Interannual variations in Earth's reflectance 1999-2007, J. Geophys. Res., 114, D00D03, doi:10.1029/2008JD010734, 2009.

Potter, G. L. and Cess, R. D.: Testing the impact of clouds on the radiation budgets of 19 atmospheric general circulation models, J. Geophys. Res., 109, D02106, doi:10.1029/2003JD004018, 2004.

Ramanathan, V.: The Role of Earth Radiation Budget Studies in Climate and General Circulation Research, J. Geophys. Res., 92, 4075-4095, 1987.

Ramanathan, V., Barkstrom, B. R., and Harrison, E. F.: Climate and the Earth's radiation budget, Physics Today, May, issue, 22-32, 1989a.

Ramanathan, V., Cess, R. D., Harrison, E. F., Minnis, P., Barkstrom, B. R., Ahmad, E., and Hartmann, D.: Cloud radiative forcing and climate: Results from the Earth Radiation Budget Experiment, Science, 243, 57-63, 1989b.

Raschke, E., Ohmura, A., Rossow, W., Charlson, B. E., Zhang, Y., Stubenrauch, C., Kottek, M., and Wild, M.: Cloud effects on the radiation budget based on ISCCP data (1991-1995), Int. J. Climatol., 25, 1103-1125, 2005.

Rossow, W. B. and Schiffer, R. A.: ISCCP cloud data products, B. Am. Meteorol. Soc., 72, 2-20, 1991.

Rossow, W. and Zhang, Y.-C.: Calculation of surface and top of atmosphere radiative fluxes from physical quantities based on ISCCP data sets 2. Validation and first results, J. Geophys. Res., 100, 1167-1197, 1995.

Schneider, S. H.: Cloudiness as a global climatic feedback mechanism: The effects on the radiation balance and surface temperature of variations in cloudiness, J. Atmos. Sci., 29, 1413-1422, 1972.

Shi, L.: Cloud radiative forcing on surface shortwave fluxes: a case study based on Cloud Lidar and Radar Exploratory Test, J. Geophys. Res., 99, 25909-25919, 1994.

Soden, B. J., Broccoli, A. J., and Hemler, R. S.: On the use of cloud forcing to estimate cloud feedback, J. Climate, 17, 3661-3665, 2004.

Solomonson, V. V. and Marlatt, W. E.: Anisotropic solar reflectance over white sand, snow and stratus clouds, J. Appl. Meteorol., 7, 475-483, 1968.

Stephens, G. L.: Cloud feedbacks in the climate system: a critical review, J. Climate, 18, 237-273, 2005.

Stokes, G. M. and Schwartz, S. E.: The Atmospheric Radiation Measurement (ARM) program: Programmatic background and design of the cloud and radiation test bed, B. Am. Meteorol. Soc., 75, 1201-1221, 1994.

Tacken, J. L. and Di Girolamo, L.: Enhanced aerosol backscatter adjacent to tropical trade wind clouds revealed by satellite-based lidar, Geophys. Res. Lett., 36, L14804, doi:10.1029/2009GL039264, 2009.

Varnai, T. and Marshak, A.: Global CALIPSO observations of aerosol changes near clouds, IEEE Geosci. Remote Sens. Lett., 8, 19-23, 2011.

Vavrus, S.: An alternative method to calculate cloud radiative forcing: Implications for quantifying cloud feedbacks, Geophys. Res. Lett., 33, L01805, doi:10.1029/2005GL024723, 2006. 
Wielicki, B. A., Harrison, E. F., Cess, R. D., King, M. D., and Randall, D. A.: Mission to Planet Earth: Role of Clouds and Radiation in Climate, B. Am. Meteorol. Soc., 76, 2125-2153, 1995.

Wielicki, B. A., Wong, T., Loeb, N., Minnis, P., Priestley, K., and Kandel, R.: Changes in Earth's Albedo Measured by Satellite, Science, 308, 825, doi:10.1126/science.1106484, 2005.
Wiscombe, W. J.: Solar radiation calculations for Arctic summer stratus conditions, Climate of the Arctic, edited by: Weller, G. and Bowling, S. A., 245-254, 1973. 